\title{
Development and Application of Classroom Equipment Repair Management System for Mobile Terminals
}

\author{
Ren Wenxuan, Yuan Weiliang \\ Teaching Information Support Center, Zhejiang Ocean University, Zhoushan, China
}

Email address:

renwenxuan@163.com (Ren Wenxuan)

\section{To cite this article:}

Ren Wenxuan, Yuan Weiliang. Development and Application of Classroom Equipment Repair Management System for Mobile Terminals. Advances in Sciences and Humanities. Vol. 7, No. 1, 2021, pp. 1-7. doi: 10.11648/j.ash.20210701.11

Received: January 7, 2021; Accepted: January 15, 2021; Published: January 28, 2021

\begin{abstract}
Currently, increasing numbers of young teachers are inclined to conduct teaching tasks via mobile phones, and therefore, in case the classroom equipment failure occurs, a mobile-phone-oriented classroom equipment repair management system needs to be developed to facilitate teachers. In addition, this kind of repair management system is also very critical for the department where interchange and renewal of the maintenance personnel often take place, for it can ignore personnel changes, and send information directly to a public mailbox of the department. In this way, on receiving the relevant message, the maintenance person on duty can respond accordingly. Thus, it can improve the maintenance efficiency and reduce the work pressure of technical staff as well. The equipment repair management system in this study adopts double line system: teachers can either choose to apply for repair from the system or directly communicate with the technician on duty via Wechat. The management of multimedia classroom is very trivial and burdensome, and title promotion for personnel in the modern education technology center is difficult, thus, there is a high turnover rate accordingly. Whereas, the use of this management system can make the maintenance demand of the classroom directly sent to the public mailbox reserved by the system. In this way, only the public mailbox needs to be handed over to the new staff, and the maintenance information can be received by all the maintenance personnels on duty at the same time, so that the teaching procedure will be guaranteed and therefore, various kinds of teaching and reform activities can carry out smoothly.
\end{abstract}

Keywords: Repair Management System, Multi-Media Classroom, Smart Classroom, Equipment Maintenance

\section{Introduction}

Now with the increasing investment in the construction of information-based teaching in schools [1], the equipment in the classroom is gradually increasing, and the simple construction method of ordinary multimedia classroom with projector and computer as the main equipment has gradually fallen behind, and the new intelligent classroom is gradually springing up.

As the teaching equipment increases, various types of classroom failures increase accordingly, since besides teachers, growing numbers of students tend to use intelligent terminals and classroom feedback screens. The traditional and simple way to paste maintenance telephone number on the classroom platform has gradually lagged behind, and out of date, which needs to continue to follow up and update the school's classroom equipment failure repair reporting system, to meet the school's daily use of teaching facilities, to ensure the smooth development of daily teaching behavior and various teaching reform and research activities. A new repair reporting platform has been developed in this study.

\section{Problems in the Traditional Repair Reporting System and Advantages of Using Repair Reporting Platform}

\subsection{Problems Existing in the Maintenance of Multimedia Classrooms in Schools}

The quantity of multimedia classroom and intelligent classroom is numerous [2], and the utilization rate is high, thus, the equipment maintenance and management directly affects teaching process and efficiency. However, the existing problems mainly consist in the shortage of technical staff in 
educational technology center, what's worse, due to "unvalued" work, difficulty in promotion and hopeless future for maintenance personnel, resulting in technicians' loosening maintenance duty. The maintenance process of classroom equipment failure in most schools is usually done like this: the teacher calls for repair when he finds the failure, classroom maintenance personnel confirms the failure and then arrives at the classroom site to solve the problem; if the maintenance personnel cannot solve the problem of equipment failure, he will contact the school equipment center first, and equipment center will ask equipment manufacturers or the maintenance service providers to repair or replace the equipment. But there are several problems in this way:

(1) Classroom equipment repair lacks feedback mechanism. Many teachers think the problem can be immediately resolved, but they do not understand the maintenance schedule, so in the next class when they find that the problem has not been solved, they will think that the maintenance personnel does not deal with the problem well. Some equipment failure may not be timely handled due to the school maintenance mechanism, for instance, in terms of aging problems of projector chips [3], maintenance personnel needs to report to the facility division to apply for repair and replacement, then the manufacturers will rush to the site for maintenance, thus, there will be a certain delay in time.

The time interval between the report of classroom equipment malfunction and the completion of repair is too long. There are many personnel and related departments who apply for repair of the equipment, and the signing procedures that involve some maintenance costs are very complicated. In addition, communication between classroom equipment maintenance personnel and teachers is usually not smooth, thus various reasons may affect the efficiency of maintenance of the equipment. For example, some teachers do not know the specific cause of equipment failure, misdescribe the fault, or even directly report the wrong classroom number, which will cause this kind of problem. Moreover, the work of maintenance personnel is constantly changing, so there are often failures that cannot be fed back to the responsible person.

(3) The concealment rate of classroom equipment damage is high. When teachers encounter failures in using equipment, they may fail to get feedback from previous communication, forget about themselves, have difficulties in communication in the early stage or even simply want to wait for another teacher to report the problems, leading to failure information not being acquired by maintenance personnel.

(4) The same fault may result in multiple repair reports, resulting in redundant maintenance information.

There is no record of the whole repair reporting process and no systematic record and archive of maintenance personnel's maintenance behaviors, leading to the lack of information and data support in the year-end work reporting and the lack of supervision and enthusiasm in work.

(6) Due to the large number of equipment in the intelligent classroom, some failures require direct feedback from the students to the maintenance personnel, but the traditional way lacks this communication channel.

\subsection{The Application of Repair Platform}

(1) The teacher can check his repair record and the maintenance personnel's reply at any time after using the repair system platform, which helps to solve the problem of lack of feedback mechanism.

(2) The teacher can feed back the problem directly to the repair platform, and send the data to the maintenance personnel accurately through the platform, which is convenient to make information found by the responsible person immediately.

(3) With the maintenance platform, it is convenient for teachers to inquire whether the current failure problem has been fed back, or whether it has been handled by the maintenance personnel, and the corresponding processing schedule, which will not only avoid repeated reports, but also let the teacher know if the failure is a new one.

(4) The whole process of failure feedback and maintenance will be recorded through the platform, which can be used for work supervision and information data recording.

(5) The QR code of maintenance system can be easily pasted in every corner of the intelligent classroom, and students can also give feedback directly through this system, which solves the problem of communication channels for students to report equipment failures to maintenance personnel.

\section{Analysis of Design Requirement of Classroom Equipment Failure Repair Reporting System}

With the continuous promotion of blended online and offline teaching in various colleges and universities, most teachers have been accustomed to using mobile apps to complete class roll call, answer questions, and organize students to conduct group discussions and other activities. As a foundation related to teaching behavior, the use of mobile phones and computers for failure repair reporting should also become an essential link in the overall behavior of teaching informatization, so as to improve the teaching experience of teachers and students and make the whole teaching behavior "intelligent" and "informationized".

As shown in Figure 1 below, we can draw up a flow chart for the entire repair and maintenance process:

We need to enable all teachers to complete the entire repair and maintenance process effectively and conveniently on their own mobile phones and computer terminals. Therefore, the following four points need to be considered in the design and implemented in the concrete design.

(1). To classify the users. The users are divided into teachers and maintenance personnel, in which the teachers can see the repair situation in the classroom, and carry out repair operations, but do not need to respond to the repair message, and maintenance personnel can not only see the repair situation, but also feedback operation on the repair message, 
and will receive the response of repair information.

(2). Repair system should be installed for both mobile phone terminal and computer terminal, that is, teachers can not only complete the repair reporting through scanning code by mobile phone, but also access and report to the repair system in the computer terminal.
(3). Reporting interface is simple. The teacher only needs to do some simple options to select work or fill in simple information to complete the entire operation.

(4). The system is designed with $\mathrm{B} / \mathrm{S}$ frame. It does not need any installation operation on the mobile phone or computer.

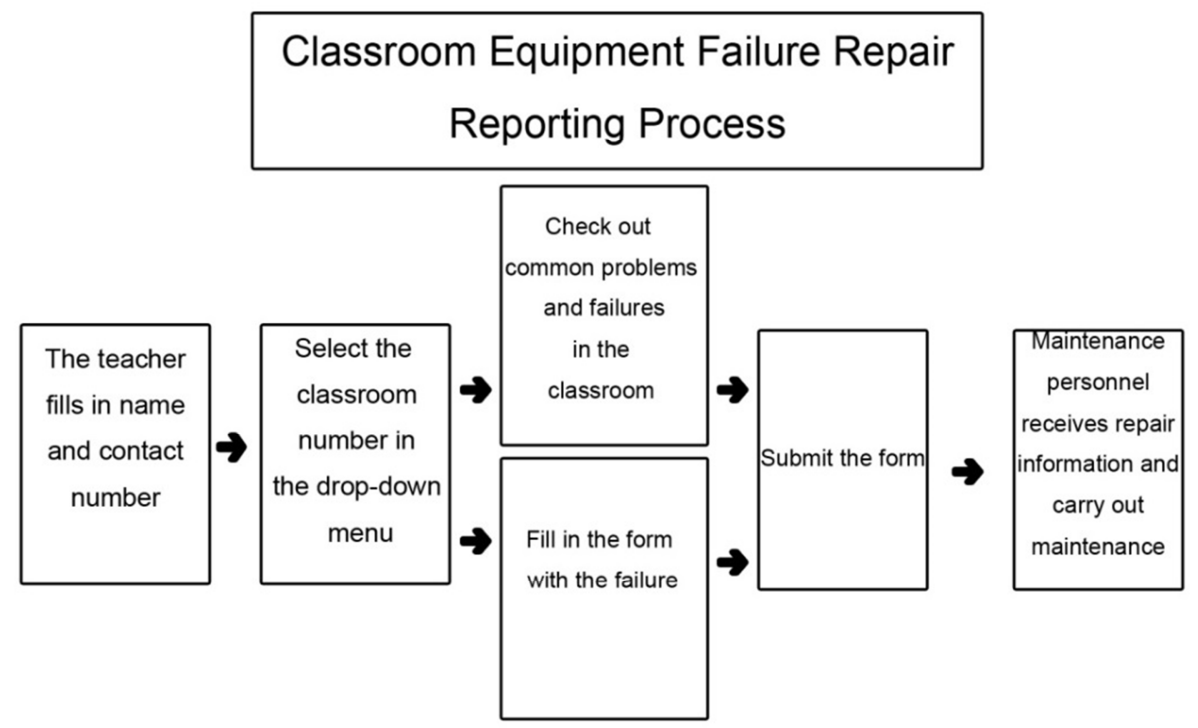

Figure 1. Flow Diagram of the Repair and Maintenance Process of Classroom Equipment Failure.

\section{Introduction to the Development and Design of the Hardware Part of the Management System}

The teaching equipment of multimedia classroom and smart classroom has a characteristic, that is, it is very easy to operate, whether it is a computer or a projector, an integrated machine or a TV LCD screen, etc., which can be often touched in daily life. In order to facilitate teachers to switch on and use equipment on hardware, the system needs to use a central controller to manage the equipment, and can read the working state of the equipment connected by these central controllers through the network. [4-7]

The specific connection diagram of central control and classroom equipment is shown in Figure 2 below:

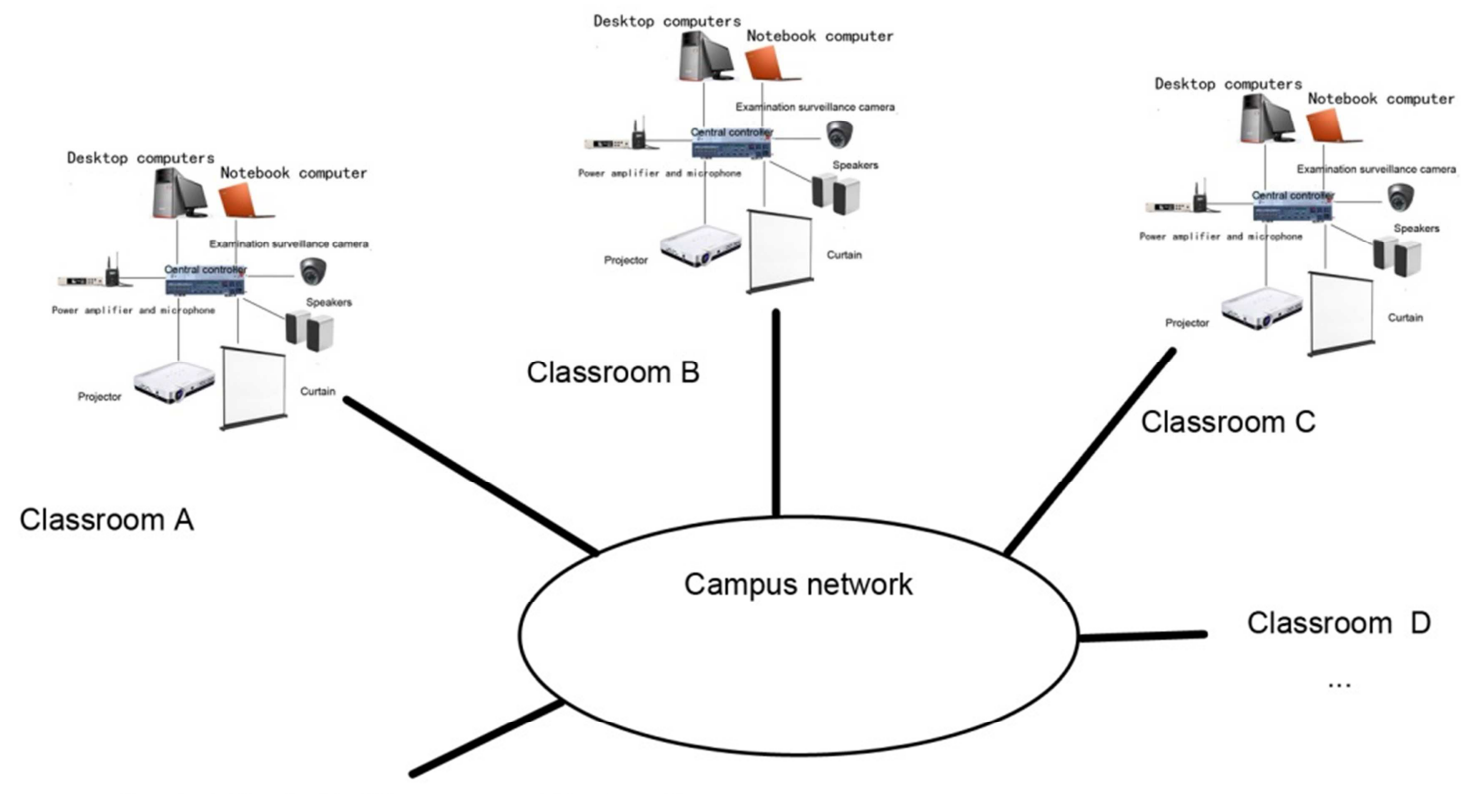

Classroom Central Controller Management System Server

Figure 2. Connection Diagram of Central Controller and Classroom Equipment. 
As shown in the figure above, the central controller is connected to various devices in the classroom through VGA cable, audio cable, RS232 control cable, power cord and mesh cable. Then each central controller is connected to the classroom's central controller management system server through the network. After the physical connection of each equipment, it is necessary to bind the IP address for each central controller and realize the control and management of each classroom by the central controller management system server through the network, so that the maintenance personnel can access the central controller management system server to understand the actual operations of all classroom equipment.

After these operations and configurations are completed, the control of the equipment by the central controller is relatively easy to achieve: for most of the equipment, only power supply instructions are required to set up boot function, such as computers, LCD TVs, and integrated machines; only the projector needs a boot command, but this can be sent through RS232 control line. The central controller can use the Keil-C51 compiler to write C program to the internal of single-chip microcomputer, and some of its code snippets are as follows.

classroomcontrolsystem -init(); //Perform system initialization operations

while (TRUE)

\{

controlcode $=$ controlcode_queue_out () ; //Gets control instructions for the system

switch(controlcode) //Determine the instruction content and perform selective operations

\{

case controlcode_action://Get the serial communication message instruction

system action _ process ()$; / /$ Execute the corresponding program

break;

case controlcode_real_ctrl:

system relay_control(); //Execute power control instructions

break;

case controlcode_channel_sw:

system channel_switch ()$;$ //Execute a video signal

converter

break; \} \}

\section{Introduction to the Development of Management System Software}

In today's society, WeChat has become an indispensable program for internet users in life. Various kinds of APP developed based on WeChat come into being one after another, which has brought great convenience to people's life and work. Based on these considerations, this paper designs a management system based on WeChat.

It is now very convenient to develop small systems based on WeChat. Compared with traditional programs written by development tools such as VB, WeChat developer tools such as Stable version of Stable Build will simplify the procedure and can make direct function calls, instead of writing a lot of codes, thus it is very convenient and easy.

The design of software is divided into two parts, one is the equipment repair reporting system, the other is the equipment failure real-time help-seeking system, respectively for different failure problems. If the equipment problems in the classroom do not affect the continuation of teaching behaviors, such as: the projector is aging and dark, or there are too many pop-up advertising windows due to computer jam, or a student's microphone in the intelligent room or the LCD panel or intelligent terminal in the discussion group below is damaged, these failures need to be repaired, but the behavior of maintenance personnel to the classroom site will inevitably affect the normal teaching process. Therefore, the failure problem can be fed back through the equipment repair system. After receiving the maintenance information, the maintenance personnel will enter the classroom for maintenance work at a time when there is no course arrangement in the classroom. In this way, the smooth teaching process can be guaranteed and the classroom equipment can be maintained.

However, if the equipment failure is so serious that teachers can not conduct the normal teaching process, they can choose the equipment failure real-time help-seeking system for help. After receiving the information, the maintenance personnel can answer and solve the problem in real time through WeChat program, or directly go to the classroom scene and solve the fault manually. The information received by the maintenance personnel in the background includes the name and the specific classroom number left when the teacher is registered, so that the maintenance personnel can contact and find the classroom that is out of order.

\subsection{Development and Design of Equipment Repair System}

\subsubsection{Main Functions of Equipment Repair System}

The main function of the equipment repair reporting system is to make it very convenient for teachers to report problems in class by scanning code with mobile phone or computer without calling or filling in a maintenance application form. This type of application does not interrupt the course, but saves both cost and time instead.

\subsubsection{Design Scheme}

The detailed design of the equipment repair system is as follows, the home page of the repair reporting website is directly generated into a shortcut, and it will be placed on the computer desktop of each classroom. when opened, a selection panel will pop up, and teachers can choose according to their own failure needs. At the same time, a QR code is generated from the website of the repair reporting system. When teachers conduct blended online and offline teaching in the intelligent classroom, they can scan this QR code by using apps such as WeChat or "Xuexi Tong", to open the website of the repair reporting system, and fill in the fault problems. The 
specific interface is shown in Figure 3 below.

As shown in Figure 3, the system categorizes the failures that often occur in the classroom and displays them on the page. When a teacher encounters a corresponding failure, he simply needs to check out the options to complete the repair request. The number of the classroom has been reserved in the system, so the teacher just needs to click down the box and select the items. After information is submitted by the teacher, it is written to the database of the repair system and displayed on the website page of the repair system. Moreover, an email is automatically sent to the reserved mailbox through the local e-mail server. Due to the automatic prompt function of the mobile email APP, when the mail is received, the maintenance staff can immediately receive the corresponding message prompted on the mobile phone after receiving the email, and respond accordingly.
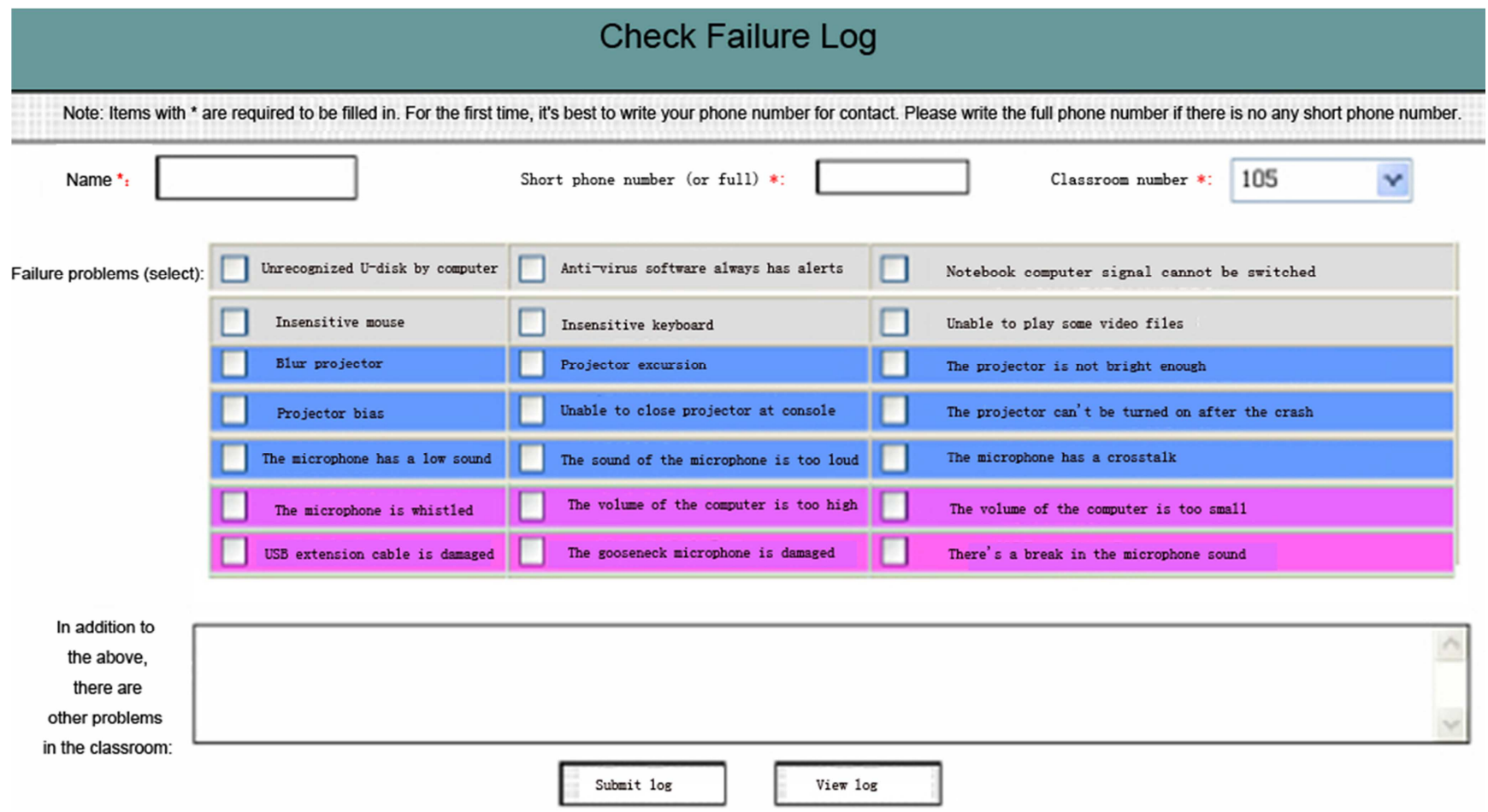

Figure 3. Failure Repair Reporting Submission Page.

\subsubsection{Write a Mail Sender}

PHP built-in mail () function can be used to realize the system's mail function, and the main code is as follows:

\$from_email="ClassroomFaultRepor@zjou.edu.cn"; //Set alarm mailbox

\$to_email="562183271@qq.com, rwx744@zjou.edu.cn"; //You can set multiple receiving email boxes for maintenance personnel

mail(\$to_email,\$subject,\$message,\$headers);//Send mail

\subsection{Development and Design of Equipment Failure Real-time Help-seeking System}

WeChat provides two ways for developers to send messages to users [8], namely group-sending interface and customer service interface. Subscriber numbers can be sent in groups once a day, and service numbers can be sent in groups four times a month. And the customer service interface can be used to send a limited number of messages to interactive users within 48 hours. According to the functions of WeChat, we can develop a WeChat official account with real-time communication function, and paste QR code of official account on the platform of the classroom. In case of equipment failure, teachers can scan the QR code to follow the public number and report the equipment failure of the classroom by sending information to the maintenance personnel. [9-12]

When teachers interact with the official account of repair report, WeChat will push the message data to the classroom maintenance personnel, who can call the customer service interface within 48 hours and send messages to the teachers who reflect the problem through a post of json packet. This way has several advantages over calling the classroom maintenance personnel directly: 1. It can save teachers' telephone bills; 2 . Some teachers are not willing to reflect the problem by means of direct telephone call, which can provide a solution for these teachers to communicate and solve the problem; 3 . In this way, besides sending text, teachers can also send voice, video, pictures and other multimedia materials in class, which can help maintenance staff better understand the equipment failure situation and make more targeted preparations in advance for solving the failure.

The WeChat official account can also be very convenient to design a few questions to query, and teachers can simply input the number to obtain the corresponding answer. For example:

(1). What's the number for the maintenance personnel?

(2). What's the duty room number and the phone number of the property management aunt?

(3). What should I do if I forget my E-card? 
(4). What should I do if there is no power supply in the classroom?

(5). What can I do if the computer fails to turn on after I insert E-card?

(6). What can I do if the projector fails to turn on after I insert E-card?

(7). What can I do when the battery of the hand-held microphone is dead?
(8). Transfer to on-line customer service.

This function is very mature, and has been used in a large number of WeChat store's "waiter" program. The specific design method is also very simple, which can be realized by simply logging in equipment failure real-time help-seeking system official account and clicking on the function menu under the "automatic reply" function. Specific setup steps are shown in Figure 4 below:

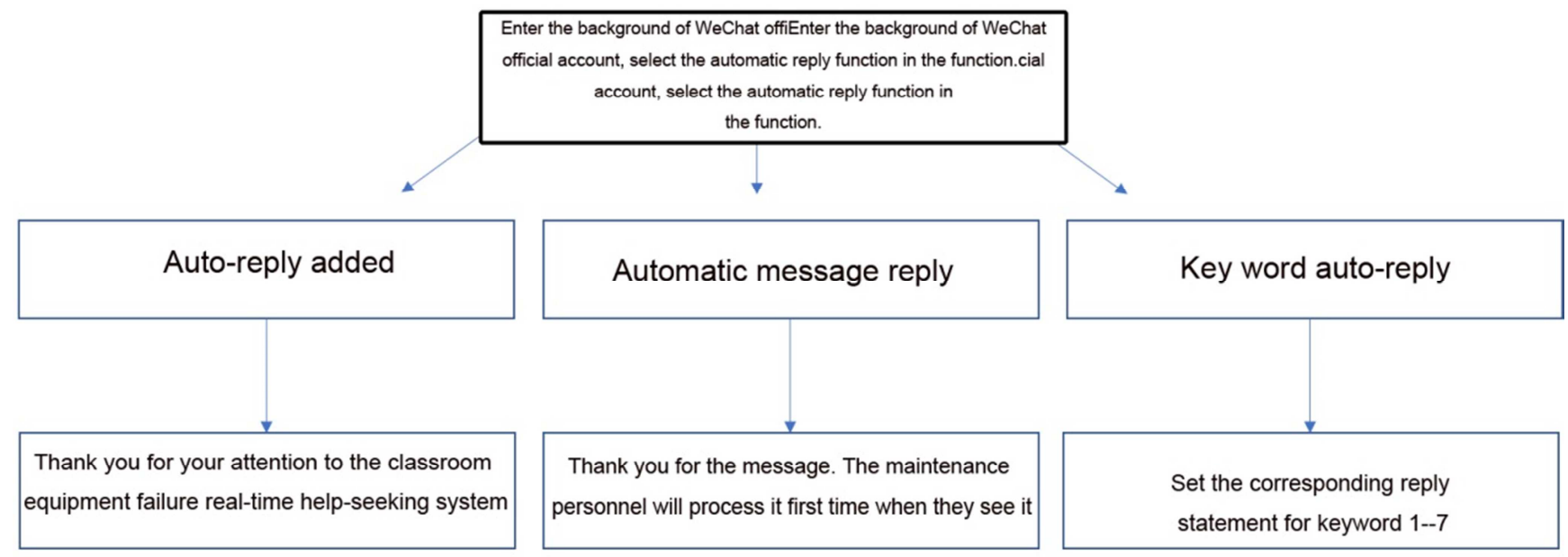

Figure 4. Official Account Help-seeking Process.

This allows teachers to get the help and support they want from the WeChat official account. And this QR code can also be posted in all corners of the classroom, so that when intelligent classroom students encounter equipment failure in the course of class, they can also scan the QR code to report equipment failure repair and other operations.

\section{Conclusion}

The modern educational technology center of Zhejiang Ocean University has been exploring the management and maintenance of multimedia classroom, from the original design of simple MCU-type central controller [13] to the study of the design of multimedia classroom failure feedback system [14], as well as management of multimedia classroom in the multi-campus [15]. Now the centralized management of classroom equipment in each campus district has been realized. However, along with the constant development of science and technology, as well as the deepening of the research of online and offline teaching, young teachers are used to completing all kinds of communication work through mobile APPs. Moreover, the newly built smart classrooms have a lot of equipment, many of which are operated and used by students. After failure, a repair reporting system can be completed without teachers or interrupting the teaching process. The classroom equipment repair management system studied in this paper can meet these requirements.

Most importantly, the management of multimedia classroom is very trivial and burdensome, and title promotion for personnel in the modern education technology center is difficult, thus, there is a high turnover rate accordingly. Whereas, the use of this management system can make the maintenance demand of the classroom directly sent to the public mailbox reserved by the system. In this way, only the public mailbox needs to be handed over to the new staff, and the maintenance information can be received by all the maintenance personnels on duty at the same time, so that the teaching procedure will be guaranteed and therefore, various kinds of teaching and reform activities can carry out smoothly.

\section{References}

[1] Wang Yunqi, Cai Jianping, Location-Based Signing to WeChat Small Program Development [J] Computer Era, 2019 (11), P67-P73.

[2] Luo Wenhuang, Sun Xun, Lu Kan, Development and Application of Failure Repair Reporting System for Training Room Based on WeChat Platform [J] Journal of Suzhou Vocational University, 2019 (3), P21-P26.

[3] Ye Renchun, Zhang Huiming, Lu Yunlong. Common Failure and Maintenance Logic of Liquid Crystal Projector in Multimedia Classroom [J]. China Educational Technology \& Equipment, 2010 (9): 84-85.

[4] He Wentao, Yang Kaicheng, Wang Yaping. The media product function of smart classroom is in collaboration Research on Adaptability in learning [J]. China audio visual education, 2017 (11): 87-95.

[5] Qiu Lanxin, Huang Zhangqin, Liang Xiaoxuan. Overview of RFID tag location sensing technology [J] Computer application research, 2017 (12): 3521-3526. 
[6] Ning Huansheng, Wang Rui. RFID major project and national Internet of things [M] (2015) Beijing: China Machine Press, 2015, 43-44.

[7] Han Ying, Wei Lin, Shao Yumei ASP.NET Dynamic website development tutorial [M] (2013) Beijing: Tsinghua University Press, 2013, 8.

[8] FangBei Studio, WeChat Public Platform Development [M]. China Machine Press, 2017, P176-177.

[9] Han Jiang. Application of QR code technology in university information management system [J]. Digital technology and application, 2014 (1): 106-106.

[10] Zhu Tianyuan. Discussion on how smart phone two-dimensional code technology can promote the development of campus informatization [J]. Wireless Internet technology, 2014 (1): 43-44.

[11] Tang Jing. Analysis on the application of QR code in Library
Reader Service $[\mathrm{J}]$. Science and technology innovation guide, 2014 (3): 208-209.

[12] Wu Dan. Discussion on the management mode of university laboratory equipment based on Mobile two-dimensional code [J]. Science and education Wenhui, 2014 (7): 77-81.

[13] Zheng Qingzhong, Zhou Yichun. Research and Implementation of the Remote Management System of Multimedia Classroom Based on Campus Network [J] Journal of Zhejiang Ocean University (Natural Science Edition), 2009 (4), P491-P494.

[14] Wang Dedong, Zhou Bin, Li Guangfei, Yang Jianzhong, Zheng Qingzhong, Design of the Failure Feedback System for Multimedia Classrooms [J] Research and Exploration in Laboratory, 2009 (6), P84-P87.

[15] Wang Xianen, Wang Dedong, Wang Wenjun, Multi-Campus Online Equipment Repairing System [J] Research and Exploration in Laboratory, 2014 (1), P259-P262. 